\title{
MODELLING COMBINED HEAT EXCHANGE IN THE LEADING EDGE OF PERSPECTIVE AIRCRAFT WING
}

\author{
Roman O. Kandinsky ${ }^{\text {a }}$, Pavel V. Prosuntsov \\ Bauman Moscow State Technical University, Moscow, Russian Federation
}

\begin{abstract}
In this paper gas dynamic numerical modelling of leading edge flow is presented and thermal loading parameters are determined. Numerical modelling of combined radiative and conductive heat transfer of the wing edge is carried out, thermal state of structure is given and the results are analyzed.
\end{abstract}

\section{INTRODUCTION}

An important direction in current aerospace technology is hypersonic aircraft development [1]. Hypersonic flight (with Mach number $>6$ ) is associated with intensive aerodynamic heating. It is known that the heat flux magnitude to the aircraft leading edges is inversely proportional to the edge radius [2]. Thus, it can be expected that it is the thermal regime for the sharp leading edges in particular that will become the biggest challenge.

The most important parameter in wing edge design is the heat flux distribution over the exterior surface. Full-scale wind tunnel tests are fairly expensive, so analytical and computational methods are used to estimate the heat flux magnitude [3]. The conventional analytical estimations of aerodynamic heating based on Fay-Riddell equation [4] do not take into account certain aspects of hypersonic flow [3]. Consequently, it is feasible to use current software packages for numerical solution of gas dynamics problems. The effectiveness of structural thermal protective elements can be very accurately estimated with mathematical modelling of radiative conductive heat transfer [1, 5-10].

The research aims to justify the design solutions with regard to the leading edge of a perspective aircraft wing based on the analysis of the combined heat transfer processes.

The research objectives include the following:

- To conduct gas dynamic numerical modelling of leading edge flow and determine the thermal loading parameters.

- To formulate physical and mathematical model of radiative conductive heat transfer in the wing edge.

- To conduct the numerical modelling of the wing edge thermal state and analyse the results.

\section{MODELLING THE LEADING EDGE FLOW}

A two-dimensional geometrical model of the leading edge with $7 \mathrm{~mm}$ radius and $6^{\circ}$ wedge angle was created. Gas stream with 1000, 2000 and $3000 \mathrm{~m} / \mathrm{s}$ speed was assumed to flow around the model. The edge surface was assumed to be smooth. The gas was described as viscous, compressible, single-

${ }^{a}$ Corresponding author: rkandinsky@mail.ru 
component with the pressure $\mathrm{P}=6,500 \mathrm{~Pa}$, temperature $\mathrm{T}=213^{\circ} \mathrm{K}$, coefficient of turbulent viscosity $\beta$ $=1.2$. A non-steady convective heat transfer process between the real gas and wing edge was viewed.

Density gradients were described with the Aungier-Redlich-Kwong equation of state [11], and the turbulent viscousity gradients with the Spalart-Allmaras model [12]. The geometrical and finite elements models are presented in Fig. 1. The modelling was performed in ANSYS Fluent 16.0 software package [13].

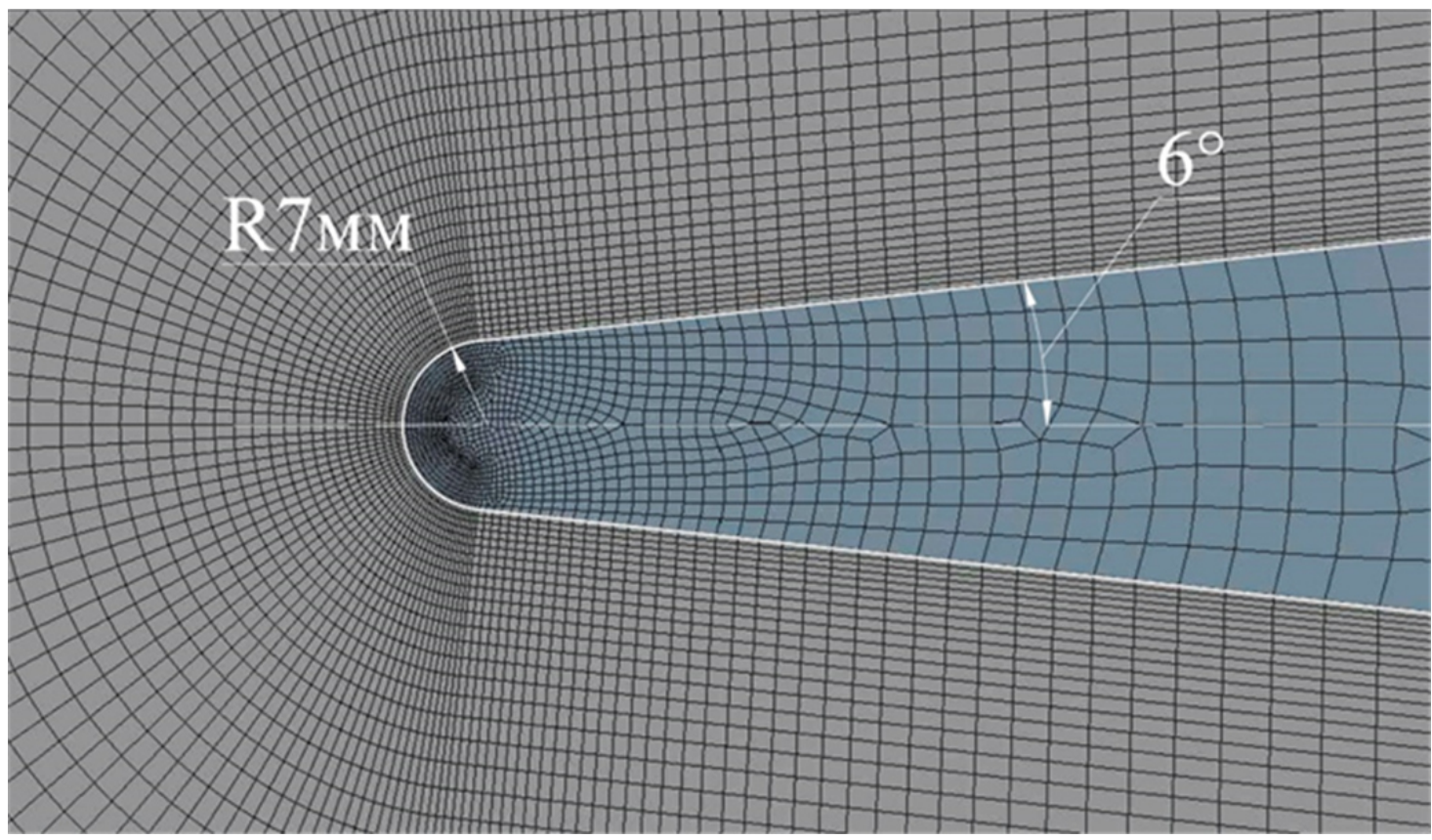

Figure 1. Geometrical and finite-elements model of the wing edge.

As a result, the temperature, density, pressure and gas flow speed fields were defined. Fig. 2 presents the gas density field for $2000 \mathrm{~m} / \mathrm{s}$ flow speed. Shock wave separation from the edge surface is visible, which is characteristic of the hypersonic flow. 


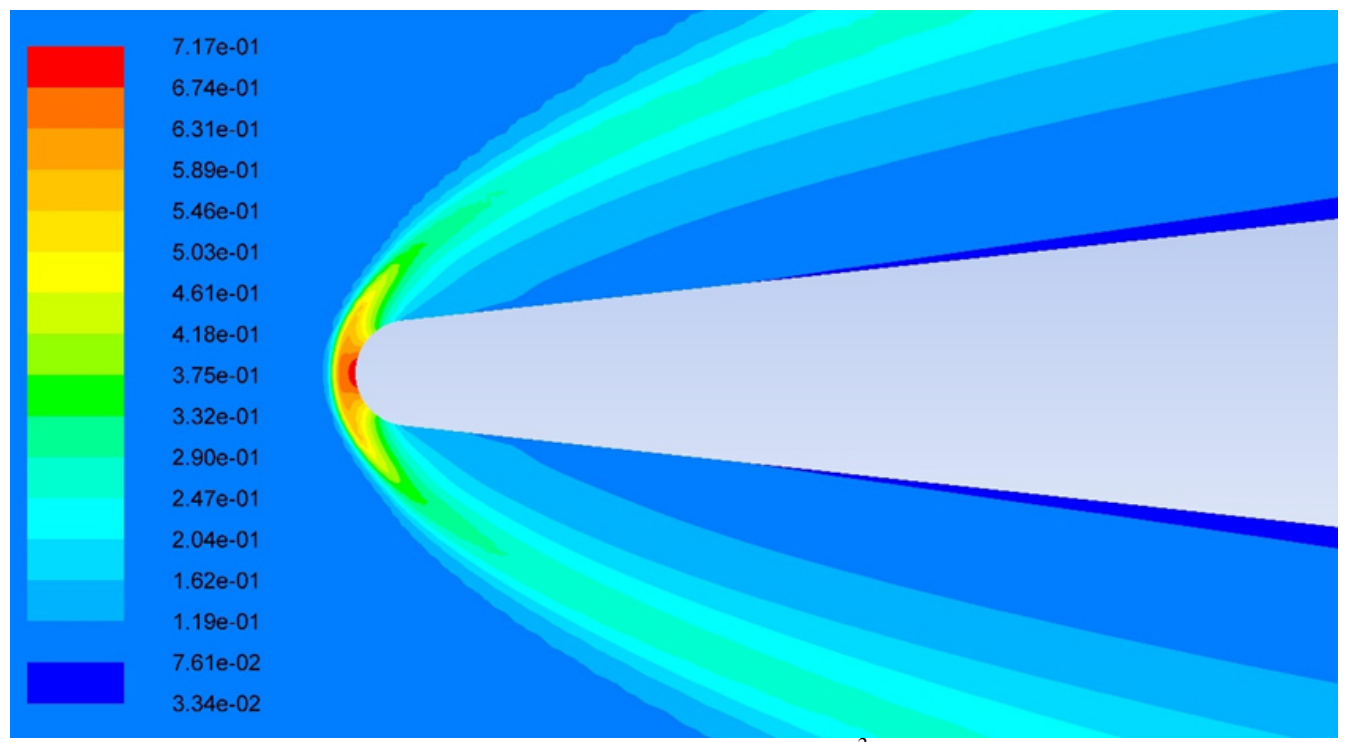

Figure 2. Gas stream density field for $2,000 \mathrm{~m} / \mathrm{s}$ flow speed, $\mathrm{kg} / \mathrm{m}^{3}$.

Heat flux density distribution over the edge surface was obtained as well (Fig.3). It is visible that the most loaded area is the edge radius limited by $10 \mathrm{~mm}$ density from the critical point. The maximal values for the heat flux density constituted 260000,1430000 and $4720000 \mathrm{~W} / \mathrm{m}^{2}$ for the flow speed of 1000,2000 and $3000 \mathrm{~m} / \mathrm{s}$ correspondingly.

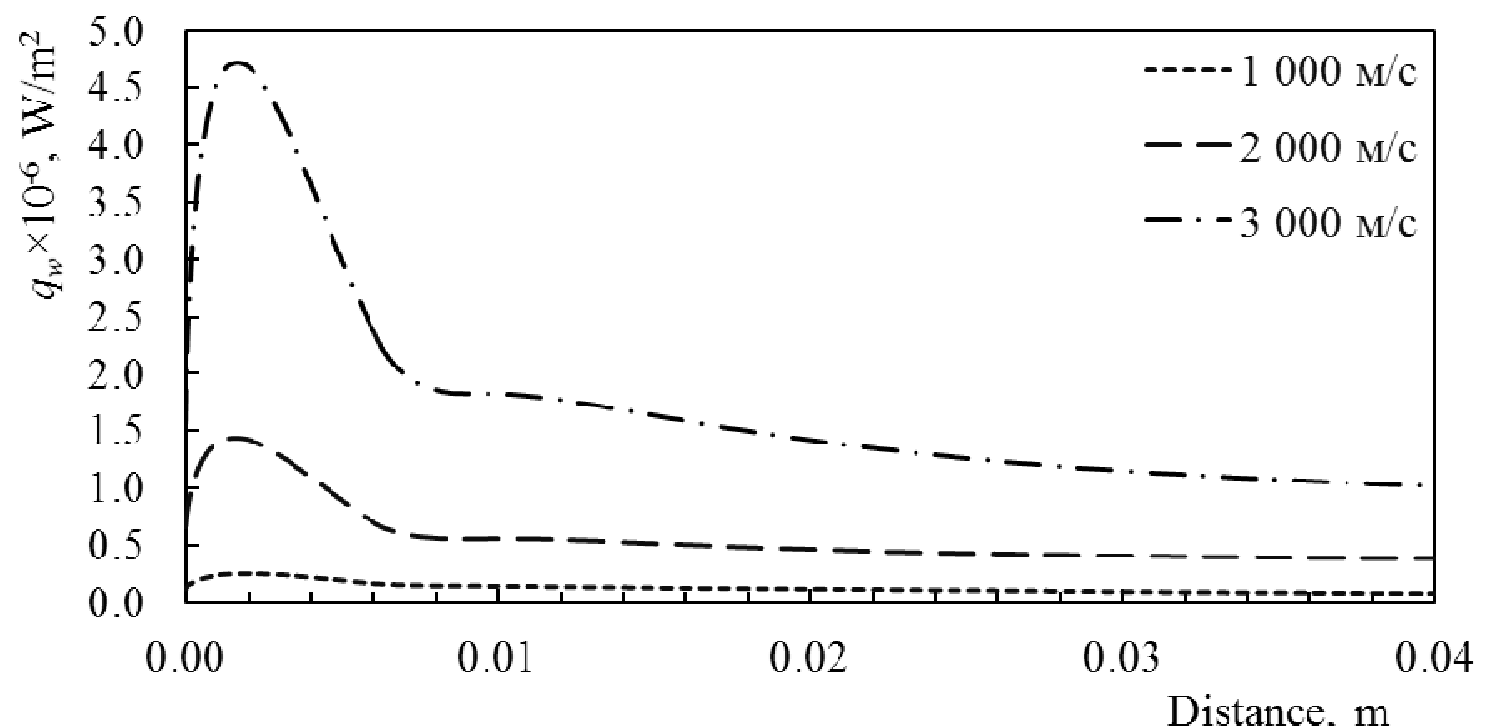

Figure 3. Heat flux density $q_{w}$ distribution over the wing edge surface, $\mathrm{W} / \mathrm{m}^{2}$.

\section{Heat transfer modelling in the wing edge section}

In hypersonic aircraft leading edges high-temperature ceramics (HTC) [14], ceramic matrix composite materials (CMC) [15], or high-porousity quartz ceramics [16] can be used [2]. A number of leading edge design variants were developed for these materials (Fig. 4). Their external profile corresponded to the gas-dynamics model. 
In order to analyze the thermal state of the design variants, combined heat transfer process was simulated. All the materials were assumed to be void-free, homogeneous, possessing temperature dependent density, heat capacity and heat conductivity. All the surfaces were assumed to be diffusely radiating grey. The emissivity coefficient was specified as non-temperature dependent. The thermal contact at the materials interface was assumed to be ideal.

The mathematical model of the process constituted a system of the three-dimensional non-steady non-linear heat conductivity equation and the radiative heat transfer equation for a system of diffusegrey surface bodies [17]. It was assumed that the outer surface is exposed to the heat fluxes obtained from the gas dynamics modelling problem (Fig. 3), with the environment temperature equaling $213^{\circ}$ $\mathrm{K}$. The simulation was performed in the ANSYS Transient Thermal $^{\circ} 16.0$ software package [13]. The series of calculations for each variant provided temperature fields.

The first variant (Fig. 4a) was based on the CMC shell reinforced with heat-resistant aircraft-grade steel elements [16]. The casing wall was $4 \mathrm{~mm}$ thick, the load-bearing elements were positioned at 140 and $320 \mathrm{~mm}$ distance from the critical point. The position of the hottest area corresponds to the position of the applied heat flux maximum - approximately $10 \mathrm{~mm}$ from the critical point. In the case of $2900 \mathrm{~m} / \mathrm{s}$ flow the temperature of the front load-bearing element reached the limit of the steel temperature operating range. For $3000 \mathrm{~m} / \mathrm{s}$ speed, the temperatures in the critical points and loadbearing elements exceed maximum values for the materials used.

The second variant (Fig. 4b) was also based on the CMC shell. But in order to block thermal radiation from the shell surface inside the structure, thermal protection screens from high-porousity quartz ceramics were positioned in the grooves of the front load-bearing element. For $2000 \mathrm{~m} / \mathrm{s}$ flow speed the front load-bearing element temperature was close to the maximally acceptable. For 3000 $\mathrm{m} / \mathrm{s}$ speed, the temperature of several elements exceeded the acceptable values.

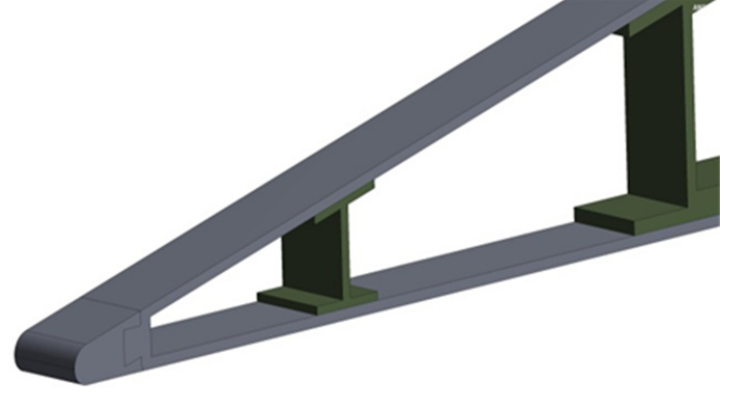

a.

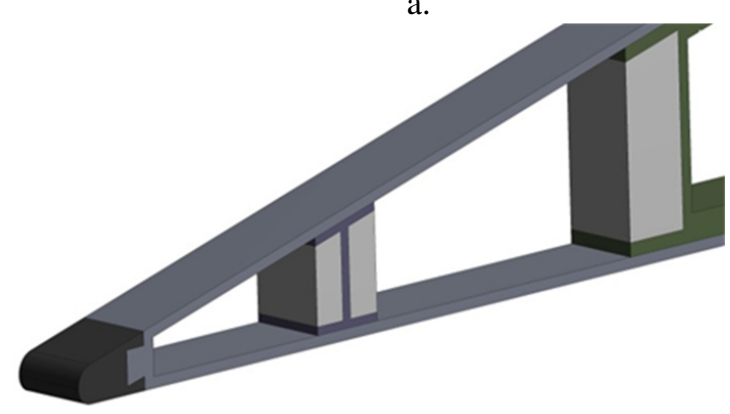

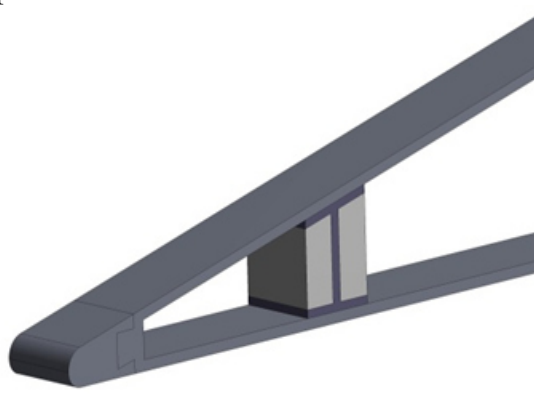

b.

c.

Figure 4. Wing edge design layouts a) variant $1 ; \mathrm{b}$ ) variant 2 : c) variant 3.

In the third variant (Fig. 4c) an additional HTC cap was installed in the most heat loaded area of the wing edge. The front load-bearing element was made out of CMC and the rear element from the heat resistant aircraftgrade steel. Apart of that an additional thermal protection screen was installed into the groove of the rear loadbearing element. At $3000 \mathrm{~m} / \mathrm{c}$ flow none of the elements had the temperature higher than the acceptable values. The temperature field for the third design variant of the wing edge for $2000 \mathrm{~m} / \mathrm{c}$ flow speed is presented in Fig.5. 


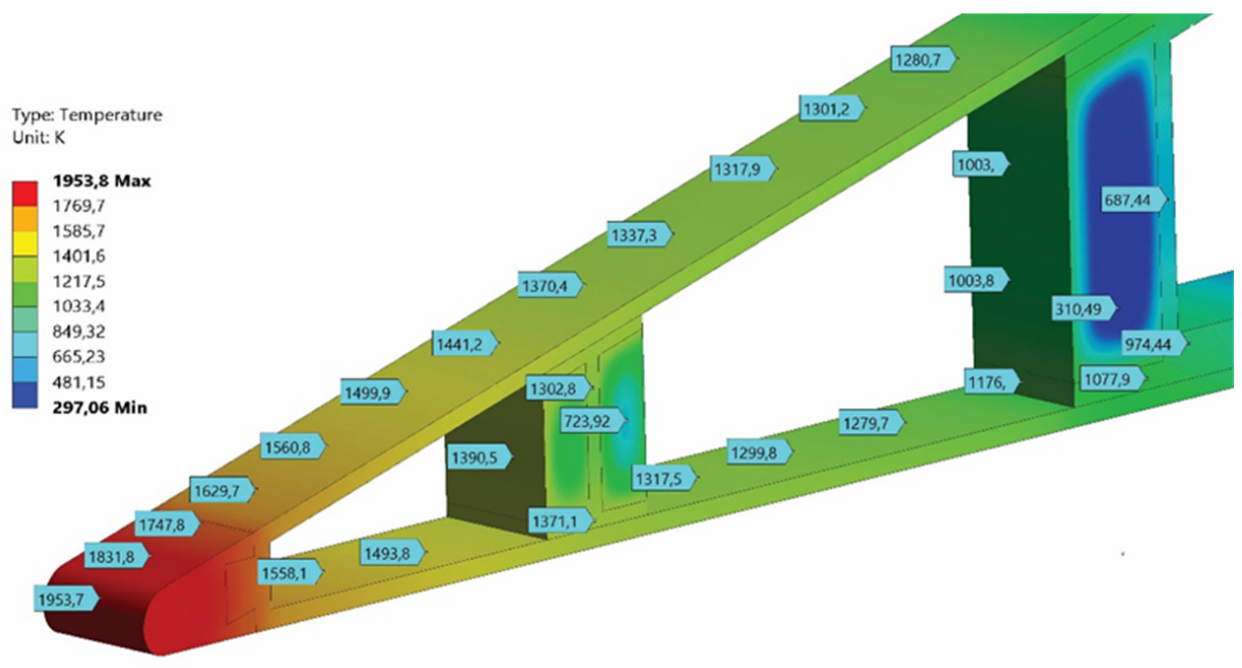

Figure 5. Wing edge temperature field.

\section{Conclusion}

By means of numerical methods of gas dynamics simulation heat load to the hypersonic aircraft wing leading edge was estimated, which enabled simulation of combined radiative-conductive heat transfer and determine its thermal state. It was demonstrated that a functioning edge structure could be created based on the combination of high-temperature ceramics, ceramic matrix composite material, highporousity quartz ceramics and heat-resistant aircraft-grade steel.

Certain results of this research were obtained within the Agreement for grant № 14.577.21.0099 with Ministry of Education and Science of Russian Federation. The unique identifier for applied research (project) RFMEFI57714X0008.

\section{References}

1. Reznik S.V. Eng. Journal: Science and Innovation 3, (2013).

2. Glass D.E. Proceed. 15-th AIAA Space Planes and Hypersonic Systems and Technologies Conference 2008-2682, (2008)

3. Bertin J.J., Cummings R.M. Annual Review of Fluid Mechanics 38, (2006)

4. Fay J.A., Riddell F.R. Journal of the Aeronautical Sciences 25, 2 (1958).

5. Dylko Yu.B., Prosuntsov P.V. Vestnik MGTU im. N.E. Baumana. Maschinostroenie 3, (2012).

6. Danilova D.A., Prosuntsov P. Vestnik MGTU im. N.E. Baumana. Maschinostroenie 3, (2012).

7. Reznik S.V., Prosuntsov P.V., Fisher W.P., et al Abstracts of the Reports and Communications of 5-th Int. Forum on Heat and Mass Transfer 7, (2004).

8. Reznik S.V., Fisher W.P.P., Martines D. et al. Journal of Engineering Physics and Thermophysics 77, 3 (2004).

9. Paderin L. Ya., Prosuntsov P.V., Reznik S. V., Fisher W.P.P. Journal of Engineering Physics and Thermophysics 78, 1 (2005).

10. Reznik S.V., Fisher W.P.P, Kalinin D. Yu. et al. Space-rocket Technology: Fundamental and Applied Problems: Proceed. of 2-nd Int. Sci. Conf. II, (2003).

11. Aungier R.H. Journal of Fluids Engineering 117, (1995).

12. Spalart P., Allmaras S. A AIAA Technical Report 92-0439, (1992).

13. ANSYS 16.0 Release Notes (ANSYS Inc., 2015). 
14. Justin J.F., Jankowiak A. Aerospace Lab Journal 3, (2011).

15. Bansal N.P. Handbook of ceramic composites (Springer Science \& Business Media, 2006).

16. Williams S., Curry D. NASA Reference Publication 1289, (1992).

17. Siegel R., Howell J.R. Thermal radiation heat transfer (New York: McGraw Hill, 1972). 